\title{
Malos tratos y violencia doméstica entre los judeoconversos hispanos en el tránsito de la Edad Media a la Moderna
}

\author{
Maltreatments and domestic violence among the converted \\ Spanish Jewish in the transition of the Middle Ages to \\ the Modern Age
}

\author{
EnRIQUe CANTERa Montenegro*
}

\begin{abstract}
RESUMEN
La lectura atenta de procesos inquisitoriales de fines del siglo XV y de los primeros decenios del XVI, permite rastrear abundantes noticias acerca del uso de los malos tratos en el seno de las familias judeoconversas españolas en el tránsito de la Edad Media a la Moderna.

El recurso a la violencia doméstica es particularmente frecuente en las relaciones señores-criados, y todo permite sospechar que este tipo de actuaciones no debía ser objeto de condena social ni de sanción penal, siempre que el castigo fuera "oportuno y moderado».
\end{abstract}

\section{PALABRAS CLAVE}

Violencia doméstica; judeoconversos; Inquisición; Baja Edad Media.

\section{ABSTRACT}

The careful reading of the Inquisition trials at the end of the $X V$ century and the first decades of the XVI century, allows us to track the abundant news about the maltreatments inside the converted Spanish Jewish families in the transition of the Middle Ages to the Modern Age. The use of the domestic violence is particularly frequent in the relations lord-servant, and everything allows us to suspect that this type of behaviours did not have to be object of social condemnation nor of penal sanction, provided that the punishment was «appropriate and moderate».

\section{KEYWORDS}

Domestic violence; converted Jewish; Inquisition; Later Middle Ages.

La documentación inquisitorial constituye una fuente inagotable de información acerca de multitud de aspectos de la sociedad y la vida cotidiana de la época, mucho más allá de su prioritaria utilización para el estudio de las más diversas cuestiones relativas a la religiosidad, a las minorías étnico-religiosas o a otros distintos grupos de la marginalidad socio-religiosa. De este modo, y por lo que ahora en

\footnotetext{
* UNED.
} 
concreto me ocupa, leyendo con detenimiento algunos de los procesos inquisitoriales promovidos a lo largo de los últimos decenios del siglo XV y los primeros del siglo XVI contra judeoconversos castellanos acusados de judaizar, es posible localizar bastante información acerca del recurso a los malos tratos y a la violencia física en el ámbito familiar, un tema que es objeto de creciente atención en la investigación medievalista y modernista ${ }^{1}$.

Como tendremos ocasión de comprobar, la mayor parte de las noticias que a este respecto he podido localizar en la documentación consultada hacen referencia a los malos tratos y a la violencia padecida por las criadas o mozas, aspecto éste en el que, consiguientemente, se centrará en buena medida mi atención. Pero afloran asimismo algunos datos acerca de los castigos físicos que sufrían los niños a manos de sus padres y maestros, o de la violencia que, en ocasiones, desataban los maridos contra sus mujeres.

En la pedagogía de la Edad Media era habitual el uso de la corrección corporal por parte de padres y maestros. De este modo, en las miniaturas de manuscritos hebreos de época medieval en las que se escenifica una escuela comunitaria de niños (havrá), es bastante frecuente representar al maestro con unas disciplinas en la mano que enseña a sus alumnos en señal de advertencia. En general, se consideraba que el castigo físico ayudaba a mantener la disciplina de los menores y que, a la larga, contribuía de forma positiva al proceso de formación y educación del niño. Es sumamente ilustrativa a este respecto la declaración que el día 1 de junio de 1505 hizo ante el tribunal del Santo Oficio de Cuenca Fernando Navarro, vecino de Almazán, quien manifestó en aquella ocasión que, podría hacer siete meses, departiendo un día con Pedro de Çincovillas, tundidor, cristiano nuevo vecino de Almazán, "sobre las crianças que davan los padres a los fijos, vio e oyó este testigo cómo dixo... Çincovillas: 'Buen siglo aya mi padre por los castigos que me dió'»?

No menos ilustrativa es la declaración realizada por Juan Álvarez, vecino de la localidad soriana de Berlanga de Duero y criado del Condestable de Castilla, en el proceso inquisitorial que fue promovido en el año 1525 contra su padre, Lázaro Álvarez. Así, tratando de demostrar que sus padres eran cristianos buenos y sinceros, en el interrogatorio de indirectas manifiesta lo siguiente:

"XVII. Yten las mesmas oraçiones de Ave María, e Pater Noster, e Credo, y Salve Regina, etc., cada noche que yba de la escuela me azía a mí dezir ${ }^{3}$, todo lo

1 Véanse a este respecto, por ejemplo, algunos de los trabajos que se recogen en el libro de CÓRDOBA DE LA LLAVE, Ricardo (Coord.), Mujer, marginación y violencia entre la Edad Media y los tiempos modernos. Universidad de Córdoba. Córdoba, 2006. En ellos pueden localizarse más amplias referencias bibliográficas que permiten una primera aproximación al estudio de este tema.

2 Archivo Diocesano de Cuenca (en adelante, ADC), Inquisición, leg. 748, 5/6, fol. 23vº. Véase CARRETE PARRONDO, Carlos y FRAILE CONDE, Carolina, Fontes ludaeorum Regni Castellae. IV. Los judeoconversos de Almazán, 1501-1505. Origen familiar de los Lainez. Universidad Pontificia de Salamanca-Universidad de Granada. Salamanca, 1987, pág. 41, parágrafo 49.

${ }^{3}$ Se refiere a su padre Lázaro Álvarez, judeoconverso vecino de Berlanga de Duero. 
qual el maestro Martín Brabo de Beleña me mostraba, e lo que erraba me lo enseñavan ellos y me castigavan quando no lo savía vien, más açotes quel maestro, y me azían yr con ellos cada día de fiesta e domingo a misa e ayudar a misa e servir en la yglesia»".

Con frecuencia las reacciones de padres y maestros eran expeditivas, y saldaban su enfado con el hijo o con el discípulo con unas bofetadas. El 3 de julio de 1505 Juan, hijo de maestre Alonso, barbero vecino de Almazán, declaró ante los inquisidores de la diócesis de Cuenca que haría unos dos años, un día que estaba en la iglesia enseñando a leer a Manuel, hijo de Ruy Díaz de Alves, cristiano nuevo vecino de Almazán, de unos ocho años de edad, vio cómo el niño se apartaba a un pilar y estaba allí un rato, sin que pudiera ver lo que hacía porque estaba de espaldas. Una vez que volvió, «este testigo fue al... pilar a ver lo que fazía... Manuel... y, como este testigo fue, falló tierra movida, y con las manos quitó la tierra y falló una cruz con un cruçifijo, pequeña, de açofar ${ }^{5}$, que estava allí enterrada, y la tomó e la alinpió e la puso en un altar, e fue al [sic] Manuel e le dixo que no avía verguença de facer aquello, e le dio dos o tres bofetadas»6.

La violenta reacción paterna obedecía en ocasiones a la impertinencia del hijo, que le interrumpía en sus actividades laborales, lo que incrementaba la irritación. Es este el caso que en 1502 refiere María, mujer de Pedro Álvarez, vecina de la localidad burgalesa de Gumiel de Mercado, quien declaró ante el tribunal de la Inquisición de Soria que «puede aver medio año... [que] este testigo estaba urdiendo una tela en casa de Françisco Gómez, texedor de lienços, christiano nuevo, veçino de la dicha villa, el qual tenía un su fijo en el portal de la casa con un libro leyendo, e como el niño estava rudo ${ }^{7} . .$. . Françisco Gómez salió del telar con melancolía e le tomó por los cabeçones ${ }^{9}$ e le dixo: 'So pena de yuiduy ${ }^{10}$ que no te levantse de aý. Fuele preguntado sy sabe otra cosa. Dixo que no, e que no lo dize por odio, salvo por descargo de su conçiencia»"11.

4 ADC, Inquisición, leg. 89/1313, fol. 84r ${ }^{\circ}$. MUÑOZ SOLLA, Ricardo, Los judeoconversos judaizantes de Berlanga de Duero (s. XV-XVI). Tesis doctoral inédita. Universidad de Salamanca, 2003, 3 vols. (vol. II, pág. 368). Esta tesis será publicada próximamente por la Fundación Cultural Profesor Cantera Burgos, de Miranda de Ebro.

5 Es decir, de latón.

6 ADC, Inquisición, leg. 719/15, fol. 10v. CARRETE, Carlos y FRAILE, Carolina, Los judeoconversos de Almazán, 1501-1505, pág. 94, parágrafo 180.

7 Áspero, violento.

8 Es decir, con irritación.

9 Parte del pelo superior a las sienes.

10 Viduy significa en hebreo «confesión del pecado». Se trata de una práctica importante en la vida religiosa judía, tanto a nivel individual (por ejemplo, la confesión especial que recitan los judíos cuando se encuentran en trance de muerte) como en el plano comunitario, en cuanto parte integrante de la liturgia sinagogal. Forma parte de las oraciones diarias, en concreto de la Oración de las Dieciocho Bendiciones (Tefillá o Amidá), que junto con la Shemá Yisrael constituye una de las dos partes principales de la liturgia sinagogal

11 Archivo General de Simancas (en adelante, AGS), Patronato Real, Inquisición, leg. 28/73, fols. $937 \mathrm{r}^{\circ}-1112 \mathrm{v}^{\circ}$ (en concreto, fol. 1063r $\mathrm{r}^{\circ}$. CARRETE PARRONDO, Carlos, Fontes ludaeorum Regni Castellae. II. El Tribunal de la Inquisición en el Obispado de Soria (1486-1502), con una valoración psicológica por María J. Castaño González. Universidad Pontificia de Salamanca - Universidad de Granada. Salamanca, 1985, pág. 84, parágrafo 165. 
Entre los judeoconversos no era infrecuente que la irritación paterna contra sus hijos viniera motivada por el incumplimiento por parte de éstos de algún precepto del judaísmo. Así se pone de manifiesto en la testificación que el día 17 de marzo de 1532 hizo Catalina, mujer de Francisco Gómez, carpintero vecino de Berlanga de Duero, en el proceso inquisitorial que fue promovido contra Isabel López de Santamaría, mujer de Îñigo de Santamaría, vecina también de Berlanga de Duero; la inculpada, que contaba en el año 1530 con unos setenta años de edad, se había convertido al cristianismo en Portugal, a donde se había trasladado tras la expulsión general de los judíos de Castilla y Aragón en 1492, retornando poco tiempo después al reino de Castilla. En su declaración ante los inquisidores, Catalina expuso que haría unos veinte años había vivido por espacio de un año en la casa de Íñigo de Santamaría, y que durante ese tiempo había visto hacer en su casa algunas cosas que no le parecían bien, como retirar el sebo de la carne o lavar la carne con muchas aguas hasta que quedaba totalmente limpia de sangre ${ }^{12}$. Asimismo señaló que había observado que nunca ponían tocino en la olla, por lo que ella se preparaba un «pucheruelo» aparte con tocino, y que una o dos veces que estaba asando un poco de tocino para almorzar vio cómo un hijo de Íñigo de Santamaría y de Isabel López de Santamaría «que se llama Dyonisio, que a la sazón era mochacho, porque pringava el pan con la grasa que corría, le dio de golpes la dicha Ysabel, su madre, estando presente el dicho Ýñigo de Santamaría, el qual le reprehendía también al dicho su hijo. Y que estavan presentes fasta que el toçino se acabase de açar, y aún casi de quemar, porque no le quedase xugo ninguno. Y que ansý lo comía después el mochacho syn sustançia»13.

En otras ocasiones, los padres reaccionaban violentamente contra sus hijos con motivo de alguna imprudencia que comprometía el secreto en el que mantenían su condición de judaizantes. Así, por ejemplo, el 5 de junio de 1505 testificó ante el tribunal de la Inquisición Marina López, mujer de Diego de Valdivieso, vecina de Almazán, quien declaró que un día de la última Cuaresma había visto delante de la casa de Juan de Almería, zapatero, cristiano nuevo vecino de Almazán, a un hijo suyo de doce o trece años de edad, que enseñaba una oración en hebreo a una hermana pequeña, llamada Marica o Catalina, de cuatro años de edad; se trataba de una oración en que decían Lecurie açarpariel «e otras palabras en garguero ${ }^{14}$, como dezían los judíos, que este testigo no entendió, y al fin dixo, alçando e abaxando la cabeça ${ }^{15}$, 'Hagoha'. Y a esto postrero vido su madre, que estava çerca, e se levantó e le dio de puñadas ${ }^{16}$, e le dixo que callase e se quitase de allí’ ${ }^{17}$.

12 De este modo daban cumplimiento al precepto de la Torá que prohíbe a los judíos el consumo de grasa de mamíferos (Levítico, VII, 22-25) y de sangre (Génesis, IX, 4; Levítico, XVII, 10-14 y XIX, 26).

13 ADC, Inquisición, leg. 118/1618, fol. 20r․ MUÑOZ SOLLA, Ricardo, Los judeoconversos judaizantes de Berlanga de Duero, vol. III, pág. 561.

${ }^{14}$ Expresión que en la documentación medieval se utiliza con cierta frecuencia para referirse a la lengua hebrea, pese a que, como señala Carlos Carrete, el hebreo tiene pocos sonidos guturales y aspirados (CARRETE, Carlos y FRAILE, Carolina, Los judeoconversos de Almazán, 1501-1505, pág. 25, parágrafo 8.

15 Se trata de una característica inclinación corporal de los judíos al orar, y que en la documentación medieval se conoce generalmente como «sabadear».

16 Es decir, golpes con los puños.

17 ADC, Inquisición, leg. 748/5-6, fol. 36r'. CARRETE, Carlos y FRAILE, Carolina, Los judeoconversos de Almazán, 1501-1505, págs. 24-25, parágrafo 8. 
Por último, la agresividad de los adultos encontraba su blanco otras veces en los niños que trabajaban bajo sus órdenes, con frecuencia como aprendices en distintos oficios artesanales. En el proceso inquisitorial promovido en los años 1513 a 1520 contra Mayor González, mujer de Pero Núñez Franco, vecina de Ciudad Real, el procurador que se encargaba de su defensa propuso a los inquisidores una serie de preguntas que habrían de ser formuladas a los testigos de abono que presentaba la defensa. Entre estas preguntas se incluye la siguiente:

«XV. Yten, si saben, etc., que la dicha [en blanco], muger de Miguel Rodríguez, vezina de Las Casas, Migualillo, su hijo, an sydo y son enemigos de la dicha Mayor Gonçález y Pero Núñez Franco, su marido, a causa que biviendo con ellos y seyendo su pastorçillo, mató un cachorro, y por ello el dicho Pero Núñez le hirió y se fue a casa de su madre y se quexó dello y se absentó muchos días que no pareçió. Y su madre mostrava enemistad y dezía que a causa de los dichos Pero Franco e su muger se le avía ydo y absentado su hijo»18.

Mucho más escasas son las noticias que he podido localizar en la documentación inquisitorial en las que se hace referencia de forma explícita a agresiones de maridos contra sus mujeres. Pese a todo, este tipo de acciones violentas no debía ser tan infrecuente como podría deducirse, y todo permite suponer, además, que la sociedad de la época era bastante permisiva en estos casos, de forma que se consideraba normal que el marido pudiera aplicar algún tipo de correctivo o, incluso, de castigo físico a su mujer cuando su conducta no fuera la considerada por él como adecuada ${ }^{19}$. En los procesos inquisitoriales promovidos contra judeoconversos acusados de judaizar no es infrecuente encontrar referencias a castigos corporales infligidos a sus mujeres por mantener algunos ritos judaicos, lo que se alegaba como argumento justificativo y prueba fehaciente de su condición de buenos cristianos. Es este el caso de Juan de Fez, judeoconverso vecino de Ciudad Real, quien, en el proceso inquisitorial que fue proseguido en los años 1483-1484 contra él y contra su mujer, declaró que «Catalina Gómez, mi muger, fizo çerimonias judaycas, las quales fueron comer pan çençeño ${ }^{20}$ algunas vezes e guisar de comer viernes para el sábado ${ }^{21}$, e yo le defendía e reñía con ella muy muchas vezes diziendo que non lo fiziese, que se echava a perder, e aún sobrel caso la ferí muchas vezes. E ella, porque de

18 Archivo Histórico Nacional (en adelante, AHN), Inquisición, leg. 155, $\mathrm{n}^{\circ} 7$, fol. 49v ${ }^{\circ}$. BEINART, Haim, Records of the Trials of the Spanish Inquisition in Ciudad Real. Jerusalem, 1974-1985, 4 vols. (véase vol. III, pág. 464).

19 CÓRDOBA DE LA LLAVE, Ricardo, «Mujer, marginación y violencia entre la Edad Media y los tiempos modernos", en CÓRDOBA DE LA LLAVE, Ricardo (Coord.), Mujer, marginación y violencia entre la Edad Media y los tiempos modernos, págs. 7-27 (véase pág. 10).

20 Pan sin levadura, que los judíos deben consumir durante los siete días de la Pascua (Pesah) por la prohibición bíblica de consumir durante esos días alimentos fermentados (hamez) y, en particular, pan con levadura (Éxodo, XII, 17-20 y Deuteronomio, XVI, 3-4).

21 Por la prohibición de preparar alimentos durante la festividad del shabat, a fin de guardar el precepto del descanso sabático. 
mí resçebía tan mala vida, algunas vezes se escusava de lo fazer, e sy lo fazía yo non la veýa...»22.

Parecido es el caso de Gil Gracián, casado con Aldonza Gracián en 1469; sus respectivos padres, judeoconversos, eran oriundos de Gerona, aunque ellos residían en Teruel. Gil ejercía profesionalmente como jurista, y tomó parte activa en el proceso promovido por los más destacados judeoconversos turolenses con el fin de evitar o, cuando menos, de retrasar la entrada de los inquisidores en la ciudad. Debía ser una persona de carácter bastante violento, lo que en diversas ocasiones se manifestaba en los malos tratos que infligía a su mujer; asimismo era profundamente rencoroso, de forma que cuando se enfadaba con ella permanecía hasta ocho días comiendo por separado. Las disputas surgían, en ocasiones, por cuestiones relativas a la conservación de costumbres y tradiciones judaicas, con frecuencia de carácter alimenticio. Así, en tanto que Gil parece que no se privaba de comer tocino, libre, conejo, anguila o congrio, alimentos todos ellos prohibidos por la religión judía, Aldonza los rechazaba de forma terminante. En otra ocasión, y con motivo de la celebración de un ayuno prescrito por la religión judía, Aldonza se propuso guardarlo, por lo que fue amenazada por su marido, quien llegó a arrastrarla por el pelo, para obligarla a comer. Es probable, no obstante, que toda esta argumentación no sea sino una artimaña de Gil para tratar de probar ante el tribunal de la Inquisición que le juzgaba por judaísmo su falta de apego a la religión judía; pero, en cualquier caso, no deja de ser profundamente significativo que para ello acuda a alegar malos tratos contra su mujer. Las actitudes violentas de Gil Gracián se manifestaban también en las relaciones con sus criados, de forma que en una ocasión «dedit baculatas (bastonazos, o golpes con un palo) dicte famule (Justa de Jabaloyas) et vulneravit eam in capite», faltando poco para que la descalabrara ${ }^{23}$.

Idéntica problemática, aunque con distintos protagonistas, es la que se deduce de las palabras de María González «la Pampana», mujer de Juan Pampán, ambos judeoconversos vecinos de Ciudad Real; así, en la confesión que hizo ante los inquisidores en el proceso que fue proseguido contra ella en los años 1483-1484, bajo la acusación de judaizar, se refiere a los correctivos que le aplicaba su marido por negarse a judaizar:

«... digo que puede aver veinte e çinco años que yo casé con él. E al tienpo que yo con él casé era buen christiano; e en ese tienpo, puede aver diez e seys años, poco más o menos, quél tomó otra opinión de se mudar de bevir en la Santa Fe Católica e fazer çerimonias judaicas e desta cabsa, porque yo no quería seguir su camino malo quél levara, me dio mui muchas feridas...; e porque yo sa-

22 AHN, Inquisición, leg. 148, n 6, fol. 14rº. BEINART, Haim, Records, vol. I, pág. 206.

${ }^{23}$ AHN, Inquisición, leg. 534, n 17. SÁNCHEZ MOYA, Manuel y MONASTERIO ASPIRI, Jasone, «Los judaizantes turolenses en el siglo XV», en Sefarad, XXXII (1972), págs. 106-140 y 307-340, y XXXIII (1973), págs. 111-143 y 325-356 (véase en concreto, vol. XXXII, pág. 321). 
bía que non traýa carne de la carneçería ${ }^{24}$ non la quería comer e desta cabsa, por muchas feridas que me dio, algunas vezes me la fazía comer ${ }^{25}$.

En algunos casos desconocemos el motivo de la agresión, ya que la documentación tan sólo nos informa acerca de las consecuencias de la misma. Es lo que sucede con doña Elvira de Barrionuevo, mujer de Valdevieso, vecina de Soria, quien testificó ante el tribunal de la Inquisición de la diócesis de Osma acerca de su abuela Catalina Ramírez, ya difunta, afirmando que haría unos quince años había oído decir a María de Orduña, también difunta, «que quando la... madre del protonotario, avuela deste testigo, vyno de Medina, que traxo mal en el ojo de un colpe que le dio su marido Juan Ramírez de Lucena, e la dicha moça avía ydo con la dicha Catalina Ramírez, avuela deste testigo, al fonsar de los judíos sobre la huesa de su padre ${ }^{26}$, e que tomó de la tierra de la dicha huesa e se la puso sobre el mal que tenía en el ojo, e llevó della a su casa para se poner ansymismo sobre el mal, e que la dixo a la dicha moça que ansí se avía revelado que con ella sanaría ${ }^{27}$. Como tendremos ocasión de comprobar más adelante, Juan Ramírez de Lucena era persona de carácter fuerte y violento, de forma que sabemos que fue autor de diversas agresiones contra su esclava Isabel «la negra», a quien no quería conceder carta de ahorro, como proponía su mujer Catalina Ramírez. ¿Tendrá algo que ver este asunto con la agresión sufrida por Catalina a manos de su marido?

Las disputas enfrentaban también a otros miembros de la unidad familiar, no siendo infrecuentes las que mantenían suegros con yernos y/o nueras. Especialmente virulenta debió ser la que enfrentó a Juana Gutiérrez, mujer de Francisco de Santa Fe, vecina de Berlanga de Duero, con su nuera Isabel de Lozoya, casada con Hernando de Santa Fe; al menos así cabe deducir de lo que se contiene en el proceso inquisitorial proseguido contra Juana, convertida al cristianismo en 1492 junto con su marido y sus dos hijos. En efecto, en la parte del proceso dedicada a las «tachas» ${ }^{28}$, la procesada propuso que se preguntara a los testigos lo siguiente:

"Il. Sy saben, etc., que la dicha Ysabel de Loçoya es mi henemiga e me quiere muy mal a causa de que, por ser muger liviana y brava, la castigava e corregía para que no lo fuese, y porque dezía que por qué reñía con su moço syn le

${ }^{24}$ Se refiere a la carnicería pública de la ciudad. La carne que llevaba Juan Pampán sería procedente de la carnicería judía, o de animales sacrificados con arreglo al ritual judío de la shehitá.

25 AHN, Inquisición, leg. 154, n 28, fol. 1v. BEINART, Haim, Records, vol. I, pág. 71.

26 Se trata de don Semuel Pesquer, judío vecino de Soria.

27 AGS, Patronato Real, Inquisición, leg. 28/73, fol. 990r'. CARRETE PARRONDO, Carlos, El Tribunal de la Inquisición en el Obispado de Soria (1486-1502), pág. 54, parágrafo 100.

Entre los judíos de época medieval era costumbre tomar tierra de la tumba de un difunto considerado como un hombre justo como remedio eficaz para sanar diversos tipos de males.

${ }_{28}$ Consiste en un capítulo del proceso inquisitorial que guarda estrecha relación con el carácter secreto de los testigos de la acusación; como el procesado no sabe quién ha testificado en su contra, tiene la posibilidad de «tachar», es decir de señalar, a personas que, por tener manifiesta enemistad con él, pudieran haber testificado de forma falsa con el fin de causarle daño. 
tener cargo ni culpa, estando yo en la cama entró dentro de mi casa y se arremetió a mí y me puso las manos en la garganta e me quería hahogar, y lo hiziera de hecho sy algunas personas no la estorvaran. Y dezía la dicha Loçoya que ella me haría quemar. E sobrello me amenaçó e me dixo muchas palabras ynjuriosas. Digan lo que açerca desto saben y le oyeron, en espeçial que me amenazó que me haría quemar, e yo quería dar quexa della e çiertas personas no me dexaron hazello»29.

Sin embargo, es en las relaciones señores-criados en las que la documentación inquisitorial relativa a malos tratos domésticos es mucho más prolija. Pese a la gran diversidad de situaciones que cabría señalar, todo parece indicar que, por regla general, criados y sirvientes formaban parte de la esfera doméstica familiar, tanto en lo que se refiere a la sociabilidad como a la autoridad; así, dependían de sus señores en cuanto a la protección y a la instrucción, lo que compensaban con su lealtad ${ }^{30}$. De este modo, y lo mismo que sucedía con la esposa e hijos, el padre de familia estaba investido de autoridad para reprender y castigar a sus criados, incluso físicamente, con la única condición de que los castigos fueran «oportunos» y moderados. La documentación analizada nos permite apuntar que eran habitualmente las amas de casa quienes reprendían y castigaban a las criadas y sirvientas domésticas, lo que, sin duda, obedece a la estrecha relación que mantenían con ellas. De este modo, son bastantes los casos que nos ofrece la documentación inquisitorial acerca de señoras que reñían y castigaban a sus sivientas, sin que muchas veces la palabra genérica "castigo» nos permita conocer con exactitud su magnitud y gravedad.

En el proceso inquisitorial promovido en 1532 contra Francisco López de Soria, judeoconverso vecino de Berlanga de Duero, en el capítulo de «tachas» se incluye a la mujer de Pedro de Fierno, vecina de Ciruela, y a Catalina, mujer de Miguel de Hornillo, vecina de Berlanga, ambas criadas en otro tiempo del procesado, y a las que él y su mujer reñían y castigaban con frecuencia. Entre las preguntas que propone el acusado que se formulen a los testigos figura la siguiente en el caso de la mujer de Pedro de Fierno:

"Yten sy saben que la dicha muger de Pedro de Fierno byvió conmigo e con mi muger una tenporada, y esta moça quando nos syrbió era muy testimoniera y mintrosa. $Y$ por esta causa reñíamos yo y mi muger muchas vezes con ella y la castigávamos, y al fin la eché de mi casa. Y desde entonçes ella tomó grande yra, odio y enemistad conmigo y con la dicha mi mugers ${ }^{31}$,

y en el de Catalina, mujer de Miguel de Hornillo:

${ }^{29}$ ADC, Inquisición, 118/1617, fol. 35rº. MUÑOZ SOLLA, Ricardo, Los judeoconversos de Berlanga de Duero (s. XV-XVI), vol. II, pág. 636.

30 MANTECÓN MOVELLÁN, Tomás A., «Las fragilidades femeninas en la Castilla moderna», en CÓRDOBA DE LA LLAVE, Ricardo (Coord.), Mujer, marginación y violencia entre la Edad Media y los tiempos modernos, págs. 279-310 (en concreto, véanse págs. 284-285).

${ }_{31}$ ADC, Inquisición, leg. 130/1683, fol. 44v․ MUÑOZ SOLLA, Ricardo, Los judeoconversos judaizantes de Berlanga de Duero (s. XV-XVI), vol. III, pág. 802. 
"Yten sy saben que la dicha Catalina era ladrona y apañava de casa todo lo que podía apañar para dar a aquel su amigo (se refiere a Juan de Serón) o a otros. Y que por estas causas mi muger la echó de casa y riñó con ella y la castigó muchas vezes, y desta causa me a tenido e tiene odio y enemistad ${ }^{32}$.

También en el proceso inquisitorial promovido en los años 1512 a 1514 contra Juana Núñez, mujer de Juan de Teva, vecina de Ciudad Real, se incluye en el capítulo de «tachas» a «Mari López, vezina de Çibdad Real, muger de Pedro de Dueñas, porque quería y quiere mal a Juana López, muger de Juan de Teva, porque muchas vezes la castigava y dezía que porque tenía tan mala lengua y era tan mala muger que dezía mal a su padre, Diego de Teva, e una vez echó de una escalera abaxo al dicho su padre, de que llegó el dicho Diego de Teva a la muerte» ${ }^{33}$.

Y en el proceso promovido también entre 1512 y 1514 contra Leonor Álvarez, mujer de Fernando Álvarez, se incluye en el capítulo de «tachas» a "Adeva Ximénez, vezina de Daimiel, que es persona raez, y pobre, e puta, e borracha e ladrona, que quería mal e quiere a la dicha Leonor Álvarez porque algunas vezes la castigava sus malos viçios, y tanbién porque que le deviemos çierta soldada de tres años, y por esto nos tenía e tiene mucha enemistad a mí e a la dicha mi muger, e asý lo ha publicado ella doquier que se falla, por lo qual, si ella testificó contra la dicha Leonor Álvarez, su dicho es ninguno e no deve ser avido ni tenido por dicho»34.

Otras referencias documentales, sin embargo, son mucho más explícitas en cuanto a los castigos infligidos a criadas y sirvientas por sus señores, haciendo alusión de forma detallada a las palizas y golpes que les propinaban. En la mayor parte de los casos las agresiones obedecían a reacciones violentas, de carácter temperamental, ante el incumplimiento de alguna instrucción transmitida, que en el caso que nos ocupa, por tratarse de documentación inquisitorial, con mucha frecuencia tenían que ver con cuestiones relativas a preceptos de la religión mosaica, normalmente de carácter dietético.

Así, en 1464 Tolosana Besante, una judeoconversa turolense de carácter fuerte y áspero, y que, al parecer, obligaba a su servidumbre a cumplir de forma escrupulosa los preceptos y ritos del judaísmo, «dio de palos» a su criada María Sánchez porque, ignorante de las costumbres de su señora, se puso a hilar un sábado, como hacía los restantes días de la semana, incumpliendo de ese modo el precepto del descanso sabático impuesto por la religión judía ${ }^{35}$.

El 4 de junio de 1505 Francisca, mujer de Pedro «el herrero», vecina de Almazán, testificó ante el tribunal de la Inquisición y afirmó que haría seis o siete años, al tiempo que había servido en casa de maestre Bernal y María Álvarez, cris-

32 Idem, pág. 808.

${ }^{33}$ AHN, Inquisición, leg. 155, n 1. BEINART, Haim, Records, vol. II, pág. 523.

${ }^{34}$ AHN, Inquisición, leg. 133, $n^{\circ}$ 21. BEINART, Haim, Records, vol. II, pág. 349.

${ }_{35}$ AHN, Inquisición, leg. 534, $n^{\circ}$ 17. SÁNCHEZ MOYA, Manuel y MONASTERIO ASPIRI, Jasone, «Los judaizantes turolenses en el siglo XV», en Sefarad, XXXII (1972), pág. 313. 
tianos nuevos vecinos de Almazán, muchas veces «su ama mandó a este testigo, delante de ella, y algunas vezes estava... su amo presente, quitar el sebo de la carne con las uñas e toda la flor, que non le dexava ninguna gordura, y fasta que lo quitava este testigo non se quitava de allí.. su ama. $Y$ algunas vezes, porque no lo quitava del todo, como ella le mandava, le dava de bofetadas» ${ }^{36}$.

Parecido es el caso que dos días después, el 6 de junio de 1505, exponía también ante el tribunal de la Inquisición Catalina, mujer de Andrés de Almándriga. Testificaba Catalina que haría tres años, cuando servía en casa de Pero Méndez, la mujer de éste, "que no comía toçino ni quería que sólamente la cuchara ni otra cosa llegase a la olla del toçino, y que muchas vezes reñía con este testigo, y aún la fería, deziendo que avía llegado la cuchara de la olla del toçino a la suya» ${ }^{37}$.

Similares son las razones que parecen estar en el origen de las agresiones sufridas por Juana González, mujer de Juan López, labrador. Así, el 8 de mayo de 1511 declaró en los procesos inquisitoriales promovidos contra Juan de la Sierra, mercader, y su mujer Beatriz González, judeoconversos vecinos de Ciudad Real, afirmando que hacía un año que había servido en casa de los procesados durante medio año, y que durante ese tiempo no les vio nunca comer tocino «y que si algún moço o moça de casa vevían con la jarra en que ellos vevían, luego la quebrantava la dicha su ama y su hermana, la muger de Villaruvia, que quemaron, lo qual vio por tres vezes, y que a este testigo e a una esclava que tenían dieron de palos porque bevían con las jarras que los dichos sus amos bevían y la dicha hermana de la dicha su ama ${ }^{38}$. La reacción violenta de Juan de la Sierra y de Beatriz González no obedecía, en mi opinión, a razones de índole higiénica sino, con toda probabilidad, al rechazo a que sus criados bebieran en sus mismas jarras tras haber ingerido tocino; no en vano, cuando llevaban tocino «lo guisavan en otra olla aparte, e que nunca ge lo vido comer en todo el dicho tienpo a la dicha su ama e amo, ni a Leonor de la Sierra, su hija, donzella, ni a Fernando de la Sierra, su hijo».

Un simple descuido, sin mayor trascendencia en cuanto al cumplimiento de un precepto religioso del judaísmo, era causa suficiente para desatar las iras de algunos amos sobre sus criados. Así, el 11 de marzo de 1489 Fátima, mujer de Gibre, moro, herrero de profesión y vecino que había sido de Turégano, y luego morador en las localidades también segovianas de Pedraza de la Sierra y de Coca, declaró en el tribunal del Santo Oficio de la diócesis de Osma y dijo que «puede aver treinta y seis o treinta y siete años que, siendo esta testigo esclaba de Diego Arias, contador ${ }^{39}$, vía cómo en Segobia enbiaba a esta testigo Elbira, muger del dicho Diego Arias, difunto, muchos viernes con un ansarón a casa de Frayme de Vi-

\footnotetext{
${ }^{36}$ ADC, Inquisición, leg. 748/5-6, fols. $34 v^{\circ}-35 r^{\circ}$. CARRETE, Carlos y FRAILE, Carolina, Los judeoconversos de Almazán, 1501-1505, pág. 27, parágrafo 12.

37 ADC, Inquisición, leg. 749/15, fol. 2v․ CARRETE, Carlos y FRAILE, Carolina, Los judeoconversos de Almazán, 1501-1505, pág. 64, parágrafo, 108.

${ }_{38}$ AHN, Inquisición, leg. 184, n 11 y leg. 153, n 14. BEINART, Haim, Records, vol. III, pág. 555 y vol. II, pág. 166, respectivamente.

${ }^{39}$ Se trata de Diego Arias Dávila, contador mayor del rey Enrique IV de Castilla.
} 
des, su cuñado de la dicha Elbira, para que le ficiese adafina ${ }^{40}$, las quales le facían en los dichos viernes en casa del dicho Frayme, y esta testigo yba los sábados por ellas y las traýa a casa del dicho Diego Arias, y las comía el dicho Diego Arias y la dicha Elbira, su muger; y aún dicho este testigo que un sábado tenía esta testigo en una bodega, a una ornilla, una adafina que abía traýdo de casa del dicho Frayme y entró un perro y ge la comió, sobre lo qual la fizo atar a este testigo la dicha Elbira, su ama, a una escalera, e le fizo dar a un hombre suyo, en su presençia, de açotes...»41.

En otras ocasiones, la irritación de los amos contra sus criados venía provocada por el deseo de éstos de cumplir con algún precepto de la religión cristiana, o por una manifestación externa de respeto hacia un símbolo sagrado del cristianismo. Este es el caso de Gracia Ruiz, mujer de Gil de Gonzalvo Ruiz, judeoconversa vecina de Teruel, quien fue procesada por la Inquisición entre 1484 y 1486 . Gracia fue acusada de escandalizar a sus criadas con su mala conducta cristiana, de forma que, como se refería, nunca la habían visto arrodillarse al paso o en la elevación del Corpus Christi; antes al contrario, cuando su criada Catalina se arrodillaba, Gracia le tiraba a la cara lo primero que venía a sus manos, insultándola y tildándola de holgazana: «Bien podéis, faciendo facienda, decir oración», por lo que Catalina había decidido no volver a arrodillarse ante el Corpus Christi en su presencia $^{42}$.

Y no menos irritación producía a los judeoconversos que sus criados les sorprendieran guardando algún precepto o rito del judaísmo, por el temor a una denuncia o, simplemente, a que una indiscreción pudiera delatar su judaísmo que tan esforzadamente mantenían en secreto. Así, en torno al año 1474 Luis Santángel, mercader judeoconverso vecino de Teruel, propinó una paliza a su criada Catalina porque le había sorprendido comiéndose unos pájaros en un día de Viernes Santo, incumpliendo el precepto de la vigilia ${ }^{43}$. Y algo similar es lo que se deduce de la declaración que en julio de 1490 hizo Catalina Sánchez, vecina de Soria, ante el tribunal de la Inquisición de la diócesis de Osma. Catalina expuso que, siendo moza pequeña, había acudido por mandato de su padre a la casa de Juan Ramírez de Lucena, padre del protonotario de Lucena, para llevar cierta cantidad de leche; pero, como la casa era grande y no encontró a nadie que la atendiera, entró y re-

40 La adafina (en hebreo, hamín, es decir «caliente») es un potaje o guiso que los judíos preparan la tarde del viernes para comer el sábado, debido a la prohibición de preparar alimentos en este día. Se componía a base de carne, garbanzos y legumbres diversas, verduras (col, puerro, acelgas, espinacas), huevos y especias (azafrán, pimienta). Una vez preparado, se colocaba en un horno o anafe y se recubría con brasas y rescoldos para que se mantuviera caliente hasta el día siguiente.

${ }^{41}$ AHN, Inquisición, leg. 1413, núm. 7, libro 5º, fol. 1601. CARRETE PARRONDO, Carlos, Fontes ludaeorum Regni Castellae. III. Proceso inquisitorial contra los Arias Dávila segovianos: un enfrentamiento social entre judíos y conversos. Salamanca. Universidad Pontificia de Salamanca - Universidad de Granada, 1986, pág. 75, parágrafo 128.

42 AHN, Inquisición, leg. 544, $n^{\circ}$ 12. SÁNCHEZ MOYA, Manuel y MONASTERIO ASPIRI, Jasone, «Los judaizantes turolenses en el siglo XV», en Sefarad, XXXIII (1973), pág. 122.

${ }^{43}$ AHN, Inquisición, leg. 547, n 7. SÁNCHEZ MOYA, Manuel y MONASTERIO ASPIRI, Jasone, «Los judaizantes turolenses en el siglo XV», en Sefarad, XXXII (1972), pág. 333. 
corrió diversas estancias hasta que llegó a un «palacio», que estaba muy barrido y muy adornado, y en el que había muchas candelas y lámparas de aceite ardiendo en la pared, lo que producía mucha claridad ${ }^{44}$. En ese «palacio» había encontrado a la mujer de Juan Ramírez de Lucena, y con ella a una moza a la que ordenó inmediatamente que la sacara de allí y que le tomara la leche que llevaba. Algún tiempo más tarde fue esta moza a la casa del padre de Catalina y le dijo a su madre: « $i A$, osadas, que nos costó caro la yda, que fue a nuestra casa vuestra hija; que nos dio de palos mi señora a mí e a otra moça, que la enbió mi señora al collado e dexó las puertas abiertas e entró vuestra hija e hallonos a mi señora e a mí adobando los candiles!» 45 .

Pero los golpes y las palizas a las criadas respondían también a otras diversas razones, no siempre relacionadas con el cumplimiento de preceptos y ritos del judaísmo. Es esto lo que sucede con Isabel López de Santamaría, mujer de Î́nigo de Santamaría, vecinos de Berlanga de Duero; así, en el proceso inquisitorial que fue promovido contra Isabel en 1530, la procesada respondió a las acusaciones vertidas contra ella por uno de los testigos de la acusación en los siguientes términos: "Al terçero testigo dixo que esta confesante es muger recogida e tenía por costumbre de çerrar sus puertas y sobirse a su cozina. $Y$ que algunas vezes se sentaba tras su puerta. Y quien a testificado esto es una criada suya, hija de Alonso Muñoz, que se llama María, porque quiere mal a esta confesante porque una vez la dio de palos porque subió desnuda, en carnes, de una cuba que estaba labando, delante de unos moços ofiçiales que estaban en su casa, e se reía con ellos» ${ }^{46}$.

Otras veces era la sospecha de infidelidad del marido con una criada o, simplemente, los celos, lo que llevaba a una señora a maltratar a su sirvienta. Es este el caso de Mayor, mujer de Juan de Villarreal, cardador residente en Ciudad Real, que había servido en casa de Francisco de Toledo y de Marina González, judeoconversos también vecinos de Ciudad Real. Así, en el proceso inquisitorial promovido contra Marina declaró su esposo Francisco de Toledo, quien alegó que su mujer «tomó tan grandes çelos della (se refiere a Mayor) que pensava que yo adulterava con ella, y en esta causa le quitava de tan mala suerte y con tanta seguridad que hasta tanto que la hechó de su casa arrastrando de los cabellos y dizyéndole que era una puta pública y mançeba de su marido e después de toda la villa. Y la dicha Mayor se fue muy apartada, amenazando a la dicha my muger, dizyendo della que era una puta judía y que ella la haría quemar, y esto comunicó con muchas personas, las quales de oýdas desto podrán deponer algunas cosas contra la dicha mi muger ${ }^{47}$.

${ }_{44}$ Se trata, con toda probabilidad, de una habitación que haría las veces de sinagoga o, quizá también, de la preparación para la celebración del shabat.

45 AGS, Patronato Real, Inquisición, leg. 28/73, fols. 940v - 941r ${ }^{\circ}$. CARRETE PARRONDO, Carlos, El Tribunal de la Inquisición en el Obispado de Soria (1486-1502), págs. 20-21, parágrafo 8.

${ }_{46}$ ADC, Inquisición, leg. 118/1618, fol. 14r ${ }^{\circ}$. MUÑOZ SOLLA, Ricardo, Los judeoconversos judaizantes de Berlanga de Duero (s. XV-XVI), vol. III, pág. 958.

47 AHN, Inquisición, leg. 155, n 4, fol. 11vº. BEINART, Haim, Records, II, pág. 26. 
Y ya para concluir, es especialmente significativo y triste el caso de Isabel, apodada «la negra», que fue esclava de Juan Ramírez, judeoconverso y mayordomo del cardenal Cisneros, quien fue procesado por el tribunal de la Inquisición en los años 1512 a 1524, siendo ya difunto. En el capítulo de «tachas» se incluye a Isabel «la negra», "la qual desde más de seys años, e muchos antes, hasta agora, continuamente a tenido y tiene henemistad capital contra el dicho Juan Ramírez e su muger e parientes e hijos, diçiéndola y mostrándola por obra y palabras, porque el dicho Juan Ramírez se servía de la dicha Ysabel como esclava, diçiéndose ella horra; sobre que truxo con él muchos debates e diferençias e publicava del dicho Juan Ramírez muchas palabras ynjuriosas, e tenía contra él e contra la dicha su muger muchos desacatamientos de henemiga. Y por ello el dicho Juan Ramírez la herió e maltrató muchas vezes, dándole muchos palos, golpes e açotes e otras heridas, de que la dicha Ysabel se tuvo por muy ofendida e ynjuriada, e tuvo e tiene todo el dicho tienpo malquerer de muerte al dicho Juan Ramírez e su muger e parientes, quexándose dellos deseándoles la muerte» ${ }^{48}$. Un poco más adelante, y en el mismo capítulo de «tachas», se afirma que Isabel «la negra» había pleiteado ante la justicia seglar en defensa de su libertad, alegando que su ama le había concedido carta de «ahorro", y consiguiendo al fin que el licenciado Mariana le concediera "cura de ahorro»; según se indica, a lo largo del pleito para conseguir su libertad, maldecía con frecuencia a Juan Ramírez y a su mujer, diciendo: «Ansý en esto me haçen andar; no basta el mal que me hizieron Juan Ramírez y sus hijos y parientes, syno traerme agora en esto, a osadas que ellos me lo paguen ${ }^{49}$, y afirmaba que «pues tan mal le avía tratado el dicho Juan Ramírez, que ella haría quemar al dicho Juan Ramírez y Florençia de Villarreal, su mujer, aunque supiese dar syete bueltas en el ynfierno" ${ }^{50}$. Uno de los testigos, llamado Alonso del Castillo, vecino de Ciudad Real, declaró conocer desde hacia catorce años a Isabel «la negra», esclava, señalando que cuando estaba aún en casa de Juan Ramírez, después de muerta su mujer, la había oído quejarse muchas veces de su amo cuando iba a buscar agua al pozo de la casa de su madre, "diziendo que ella es horra y podía hazer lo que quisiese, y que el dicho Juan Ramírez, su amo, la hería e dava de palos e la descalabrava porque ella no quería hazer alguna cosa que le mandava el dicho Juan Ramírez, diziéndole que era horra. Y que este testigo la vio descalabrada en la cabeça más de dos y de tres vezes. Y la dicha negra dezía que su amo la avía descalabrado. Y otra vez le dixo que un hijo suyo, el mayor, la avía descalabrado. $Y$ entonçes, quando venía descalabrada, le oýa dezir este testigo a la dicha Ysabel, negra, que en mala ynquisiçión y en mala hoguera avía de ver morir a todos los de su casa, deziéndolo por el dicho Juan Ramírez y todos los de su casa ${ }^{51}$.

En definitiva, los casos aquí expuestos considero que son expresión manifiesta de unas actitudes y comportamientos que debían ser habituales en la época de es-

\footnotetext{
48 AHN, Inquisición, leg. 176, n 4, fol. 87rº. BEINART, Haim, Records, vol. III, págs. 158-159.

49 Idem, pág. 159.

50 Idem, fol. $87 \mathrm{v}^{\circ}$, págs. 160 .

51 Idem, fol. $177 v^{\circ}$, págs. $227-228$.
} 
tudio. El uso del castigo corporal como pedagogía correctiva era visto con naturalidad, tanto en la escuela, en las relaciones maestros-estudiantes, como en el hogar, en las relaciones entre el «paterfamilias» y los restantes miembros de la unidad familiar - mujer, hijos-y, muy en particular, entre amos y criados y esclavos.

Por otra parte, ninguna diferencia existiría en estos modos de actuar entre cristianos viejos y cristianos nuevos, y lo mismo cabe decir respecto de los judíos. Por lo tanto, en mi opinión, estos comportamientos obedecen a idénticos patrones socio-culturales, muy arraigados en la sociedad medieval, y a actitudes de carácter temperamental.

En último término, todo hace pensar que los correctivos físicos, y aún las acciones fuertemente violentas que han sido descritas en algunos casos, contaban con la comprensión o, cuando menos, con la permisividad social y legal; es lo que cabe deducir del hecho de que sean los propios autores de las palizas quienes las aleguen en los procesos inquisitoriales. Es cierto que la Inquisición era otra jurisdicción procesal, que se encargaba tan sólo de los delitos contra la fe religiosa, y que, sin duda, sería de mucha mayor gravedad una condena como judaizante que un delito por agresiones, pero, en cualquier caso, no deja de llamar la atención que se aleguen actos violentos como causa justificativa de una enemistad y de una acusación falsa. En la misma línea, y como se deduce de algunas de las declaraciones de testigos en los procesos inquisitoriales, hay personas que manifiestan conocer que se infligían malos tratos contra criadas y sirvientas sin que, por el contrario, hicieran nada al respecto. $Y$ tampoco parece que los propios maltratados denunciaran las agresiones sufridas, en algún caso de cierta gravedad, como hemos tenido ocasión de comprobar, lo que hace pensar en que no tendrían demasiada confianza en obtener una satisfacción o, quizá también, en que la satisfacción de carácter legal que pudieran obtener no compensaría las consecuencias que para ellos podrían derivarse de denunciar a sus señores. 